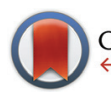

CrossMark \&lick for updates

Cite this: Dalton Trans., 2016, 45 16026

Received 1st July 2016

Accepted 17th August 2016

DOI: $10.1039 / c 6 d t 02630 c$

www.rsc.org/dalton

\section{Dinuclear uranium complexation and manipulation using robust tetraaryloxides $\uparrow$}

\author{
Jordann A. L. Wells, Megan L. Seymour, Markéta Suvova and Polly L. Arnold*
}

Two lower-oxidation state uranium cations can be readily combined in a robust, yet flexible and derivatisable, tetraaryloxide ligand framework, affording a new platform at which to use the multi-electron reductive capacity of the two actinide centres.
While single organometallic uranium centres are often capable of binding and reducing inert small molecules such as dinitrogen and carbon oxides, the most notable levels of activation and transformations are achieved almost exclusively by the combination of two uranium cations around one substrate. ${ }^{1,2}$

For example, dinitrogen overpressures as high as $80 \mathrm{psi}$ are required to stabilise the terminal $\left[\left(\mathrm{Cp}^{*}\right)_{3} \mathrm{U}\left(\eta^{1}-\mathrm{N}_{2}\right)\right]{ }^{3}$ and the first molecular uranium carbonyl $\left[\left(\mathrm{Me}_{3} \mathrm{SiC}_{5} \mathrm{H}_{4}\right)_{3} \mathrm{UCO}\right]$ showed reversible $\mathrm{CO}$ binding in solution. ${ }^{4}$ However, two molecules of uranium tris(aryloxide) or tris(siloxide) $\mathrm{UX}_{3}\left(\mathrm{X}=\mathrm{O}-2,4,6-{ }^{t} \mathrm{Bu}_{3} \mathrm{C}_{6} \mathrm{H}_{2}\right.$, $\left.\operatorname{OSi}\left(2,4,6-\mathrm{Me}_{3} \mathrm{C}_{6} \mathrm{H}_{2}\right)_{3}\right)$ in combination can effect the reduction of $\mathrm{N}_{2}$ to such an extent that the molecule $\left[\mathrm{X}_{3} \mathrm{U}^{\mathrm{IV}}\left(\mu-\eta^{2}: \eta^{2}-\mathrm{N}_{2}\right)\right.$ $\mathrm{U}^{\mathrm{IV}} \mathrm{X}_{3}$ ] is stable in boiling toluene, and can reductively couple $\mathrm{CO}$ at ambient temperature and pressure to the ynediolate complex $\left[\mathrm{X}_{3} \mathrm{U}^{\mathrm{IV}}(\mathrm{OCCO}) \mathrm{U}^{\mathrm{IV}} \mathrm{X}_{3}\right],{ }^{5,6}$ with further $\mathrm{C}-\mathrm{H}$ and $\mathrm{C}-\mathrm{C}$ bond formations possible. The conversion of aryl $\mathrm{C}-\mathrm{H}$ to $\mathrm{C}-\mathrm{B}$ bonds has also been possible in di-uranium(arene) complexes $\left[\mathrm{X}_{2} \mathrm{U}^{\mathrm{IV}}\left(\mu-\eta^{6}: \eta^{6}-\mathrm{C}_{6} \mathrm{H}_{5} \mathrm{R}\right) \mathrm{U}^{\mathrm{IV}} \mathrm{X}_{2}\right](\mathrm{R}=\mathrm{H}$, alkyl, aryl $){ }^{7}$ The recently reported reductive activation of $\mathrm{CO}_{2}$ by pairs of the uranium complexes $\left[\mathrm{U}\left(\eta-\mathrm{C}_{8} \mathrm{H}_{6}\left\{\mathrm{SiR}_{3}\right\}_{2}\right)\left(\eta-\mathrm{Cp}^{\mathrm{R}^{\prime}}\right)\right]\left(\mathrm{R}=\mathrm{Me},{ }^{\mathrm{i}} \mathrm{Pr} ; \mathrm{R}^{\prime}=\mathrm{Me}_{4} \mathrm{H}\right.$, $\mathrm{Me}_{5}, \mathrm{Me}_{4}{ }^{\mathrm{i}} \mathrm{Pr}, \mathrm{Me}_{4} \mathrm{SiMe}_{3}, \mathrm{Me}_{4} \mathrm{Et}$ ) has been particularly instructive since the product (carbonate, oxo-bridged, or desirable $\mathrm{C}-\mathrm{C}$ coupled oxalate) formed by trapping between the two uranium centres depends on the steric accessibility to the two U centres (rather than the redox capability). ${ }^{8,9}$

All these results suggest that a ligand pre-organised to hold two reducing $U$ centres would be desirable if these small molecule activations are to be rendered catalytic, or better controlled. In collaboration with Love, we recently reported the use of expanded Pacman-shaped N-donor macrocycles to

EaStCHEM School of Chemistry, The University of Edinburgh, The King's Buildings, Edinburgh EH9 3FJ, UK. E-mail: Polly.Arnold@ed.ac.uk; Fax: +44 (0)130 650 6453; Tel: +44 (0)130650 5429

$\dagger$ Electronic supplementary information (ESI) available: Full synthetic and characterising data. Crystallographic tables. CCDC 1478886-1478892. For ESI and crystallographic data in CIF or other electronic format see DOI: 10.1039/ c6dt02630c combine two $\mathrm{U}^{\mathrm{III}}$ centres at a distance suitable for trapping a di-or triatomic fragment, but have been unable as yet to isolate complexes in which no X-ligand is coordinated between the two U centres. ${ }^{10,11}$ Recognising the strength of the U-aryloxide bond in a range of $U$ oxidation states, ${ }^{7,12-16}$ we have developed a two-hour, one-pot, large-scale synthesis of three closely related analogues of a known arene-bridged tetraphenol ${ }^{17}$ in order to isolate and study the first O-donor compounds containing two discrete $\mathrm{U}^{\mathrm{III}}$ or $\mathrm{U}^{\mathrm{IV}}$ centres in a single molecule, in geometries pre-organised for small molecule binding. The three phenols used here are $\mathrm{H}_{4} \mathrm{~L}^{\mathrm{P}}$ and $\mathrm{H}_{4} \mathrm{~L}^{\mathrm{M}}$, and phenylsubstituted $\mathrm{H}_{4} \mathrm{~L}^{\mathrm{P}^{*}}$, Fig. 1 .

Bimetallic salts of the phenols closely related to $\mathrm{H}_{4} \mathrm{~L}^{\mathrm{P}}$ and $\mathrm{H}_{4} \mathrm{~L}^{\mathrm{M}}$ in Fig. 1 (with $\mathrm{R}_{1}=\mathrm{R}_{2}={ }^{t} \mathrm{Bu}$ ) have been demonstrated to be excellent ring opening polymerisation initiators for monomers including lactide (by $\mathrm{H}_{2} \mathrm{~K}_{2} \mathrm{~L}^{\mathrm{P}}$ and $\mathrm{H}_{2} \mathrm{~K}_{2} \mathrm{~L}^{\mathrm{M}}$ adducts), ${ }^{18}$ epoxide (by bis-Al ${ }^{\mathrm{III}}$ adducts of $\mathrm{L}^{\mathrm{P}}$ with $\mathrm{R}_{1}=\mathrm{R}_{2}={ }^{t} \mathrm{Bu}$ ), ${ }^{19}$ and $\varepsilon$-caprolactone (by bis-Nb or Ta adducts of $\mathrm{L}^{\mathrm{P}}$ with $\mathrm{R}_{1}=\mathrm{R}_{2}=$ $\left.{ }^{t} \mathrm{Bu}\right) \cdot{ }^{20} \mathrm{X}$-ray structural analyses in some of these complexes demonstrate a ligand flexibility that enables the metals to reside on the same or opposite sides of the central arene bridge. $^{19,21}$

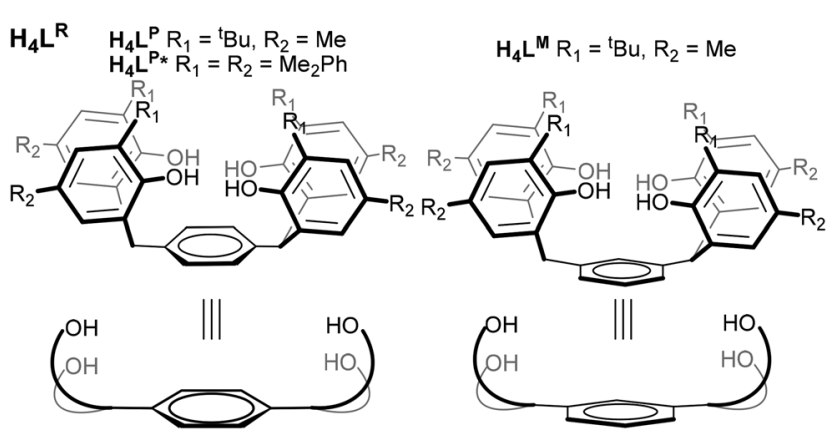

Fig. 1 The substituted tetraphenols $\mathrm{H}_{4} \mathrm{~L}^{\mathrm{R}}$ (with both para and meta substituted arene cores) and the new aryl-substituted $\mathrm{H}_{4} \mathrm{~L}^{\mathrm{P} *}$. 
Both salt metathesis and protonolysis routes allow access to diuranium complexes of the tetraphenolates, as shown in Scheme 1.

First, treatment of the in situ formed dicalcium salt $\mathrm{Ca}_{2} \mathrm{~L}^{\mathrm{R}}$ $\left(\mathrm{R}=\mathrm{P}, \mathrm{P}^{*}\right)$ or tetrapotassium $\mathrm{K}_{4} \mathrm{~L}^{\mathrm{R}}(\mathrm{R}=\mathrm{M})$ with two equivalents of $\mathrm{UI}_{4}(\text { diox })_{2}\left(\right.$ diox $=\mathrm{O}\left(\mathrm{CH}_{2} \mathrm{CH}_{2}\right)_{2} \mathrm{O}, 1,4$-dioxane $)$ in THF or dioxane affords the green crystalline diuranium target complexes after work-up to remove salt by-products. The diuranium complexes $\left[\left\{\mathrm{UI}_{2}(\mathrm{~S})_{n}\right\}_{2} \mathrm{~L}^{\mathrm{R}}\right], \mathbf{1}^{\mathrm{R}},(\mathrm{R}=\mathrm{P}: \mathrm{S}=\mathrm{THF}, n=3$ or $\left.\mathrm{S}=\operatorname{diox}, n=2 ; \mathrm{R}=\mathrm{P}^{*}: \mathrm{S}=\mathrm{THF}, n=2 ; \mathrm{R}=\mathrm{M}: \mathrm{S}=\mathrm{THF}, n=2\right)$ can be isolated after work-up in excellent yields (65-80\%).

Second, treatment of the proligand $\mathrm{H}_{4} \mathrm{~L}^{\mathrm{R}}$ with two equivalents of the $\mathrm{U}^{\mathrm{IV}}$ metallacyclic silylamide $\mathrm{UN}_{2}{ }_{2}\left(\mathrm{~N}\left(\mathrm{SiMe}_{3}\right)\right.$ $\mathrm{SiMe}_{2} \mathrm{CH}_{2}$ ) results in full deprotonation of all four acidic phenols to afford the unsolvated, yellow, crystalline $\left[\left\{\mathrm{UN}^{\prime \prime}\right\}_{2} \mathrm{~L}^{\mathrm{R}}\right] 2^{\mathrm{R}}\left(\mathrm{R}=\mathrm{P}, \mathrm{P}^{*}, \mathrm{M}\right)$, after work-up to eliminate the volatile, hexane soluble by-product $\mathrm{HN}^{\prime \prime}$, in essentially quantitative yields.

Complexes $\mathbf{1}^{\mathbf{R}}$ and $2^{\mathbf{R}}$ have been fully characterised, including by single crystal X-ray diffraction. The in-situ synthesis of the calcium salts are described below as they have proven ideal

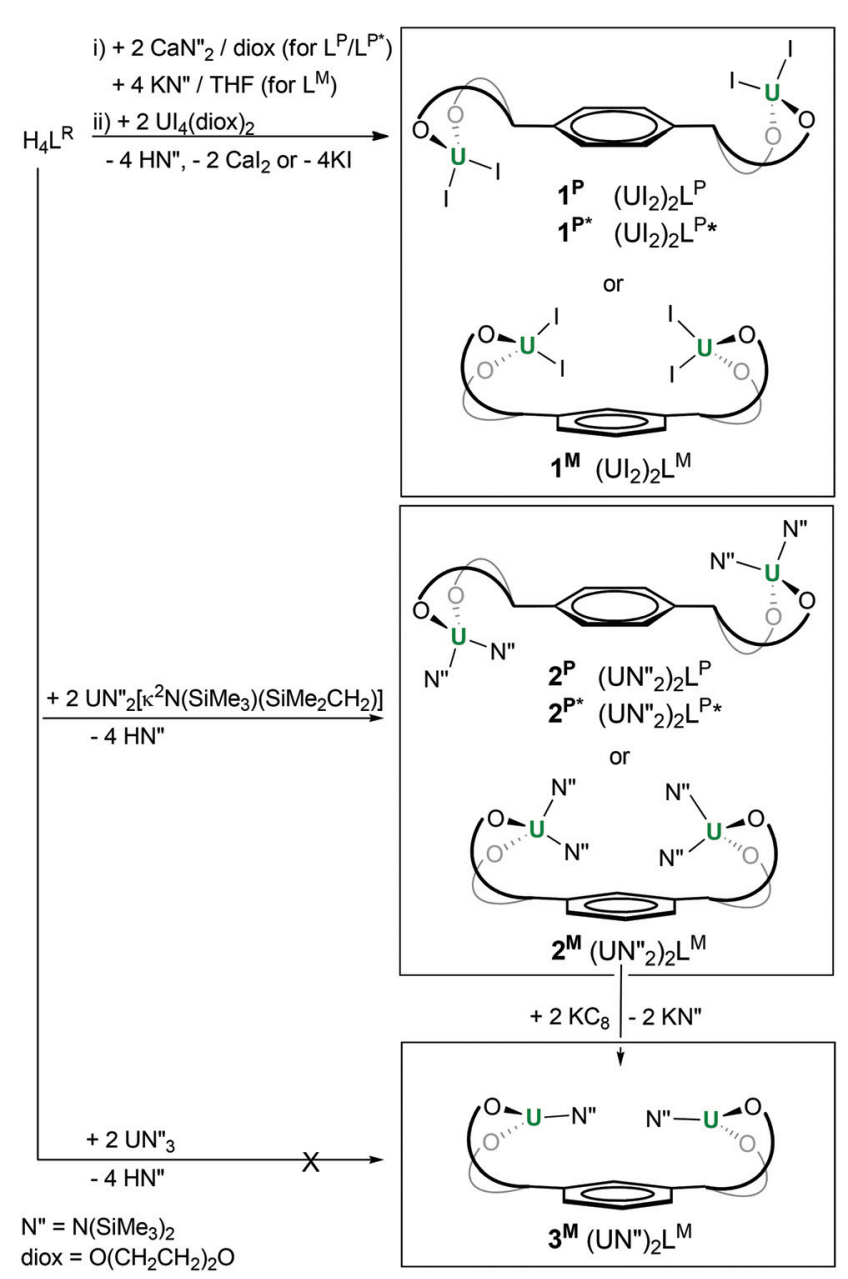

Scheme 1 Syntheses of $\left(U^{\prime V}\right)_{2}$ and $\left(U^{\prime \prime \prime}\right)_{2}$ complexes of bridged tetraaryloxide ligands $\mathrm{L}^{\mathrm{P}}, \mathrm{L}^{\mathrm{P} *}$ and $\mathrm{L}^{\mathrm{M}}$. metathesis precursors for some, since Group 1 bases often afford compounds that retain one or more bridging aryloxide protons. $^{18}$

In our hands, direct syntheses of uranium(III) analogues of $\mathbf{1}^{\mathbf{R}}$ and $\mathbf{2}^{\mathbf{R}}$ from uranium(III) halide and amide starting materials were unsuccessful. We therefore investigated the electrochemical and chemical reduction of the uranium(Iv) complexes. The $\mathrm{U}^{\mathrm{IV} / \mathrm{III}}$ redox couple is known to range from -2.78 to $-1.83 \mathrm{~V}$ versus ferrocene depending on the ligand environment. ${ }^{1,22,23}$ The cyclic voltammetry data show that the complexes $\mathbf{1}^{\mathbf{R}}$ and $2^{\mathbf{R}}$ have one wave in the negative potential region attributable to the single electron reduction of both metal centres at the same time, and confirming the absence of $\mathrm{U}^{\mathrm{IV}}-\mathrm{U}^{\mathrm{IV}}$ electronic communication through the ligand in all cases. The potentials of the complexes are collated in Table 1 and suggest that the uranium(III) complexes should be chemically accessible from a reaction with common one-electron reductants such as group 1 metals. The treatment of $2^{\mathbf{M}}$ with two equivalents of $\mathrm{KC}_{8}$ affords dark purple di-U $\mathrm{U}^{\mathrm{III}}\left[\left\{\mathrm{UN}^{\prime \prime}\right\}_{2} \mathrm{~L}^{\mathrm{M}}\right]$, $3^{\mathbf{M}}$ in $63 \%$ yield after workup, which has been characterised by multinuclear NMR spectroscopy and elemental analysis, Scheme 1.

Complexes 1, 2 and 3 are soluble in hot THF, dioxane, pyridine and arene solvents. The ${ }^{1} \mathrm{H}$ NMR spectra of the iodide complexes 1 are moderately shifted by the $\mathrm{U}^{\mathrm{IV}}$ centres with resonances in the range 14 to $0 \mathrm{ppm}$ whereas the amide complexes $\mathbf{2}$ are more significantly shifted with proton resonances spanning from 40 to $-20 \mathrm{ppm}$.

Interestingly, following reduction of $2^{\mathbf{M}}$ to give $3^{\mathbf{M}}$, the chemical shift range is decreased and proton resonances occur between 22 and $-13 \mathrm{ppm}$. The ${ }^{29} \mathrm{Si}$ resonance of the silylamide atom occurs at around $-230 \mathrm{ppm}$ for both $2^{\mathbf{P}}$ and $2^{\mathbf{M}}$ and is shifted to $-100 \mathrm{ppm}$ in $3^{\mathbf{M}}$.

Single crystals of $\mathbf{1}$ and $\mathbf{2}$ were grown, details for which are in the ESI. $\dagger$ The molecular structures of $\mathbf{1}^{\mathbf{P}}, \mathbf{1}^{\mathbf{P}}, \mathbf{1}^{\mathbf{M}}, \mathbf{2}^{\mathbf{P}}$ and $\mathbf{2}^{\mathbf{M}}$ are shown in Fig. 2 and 3 ; that for $2^{\mathbf{P}^{*}}$ is in the ESI $\dagger$ along with the structure of a dioxane solvate of $\mathbf{1}^{\mathbf{P}}, \mathbf{1}^{\mathbf{P}}$ (dioxane).

The uranium centre in $\mathbf{1}^{\mathbf{P}}$ is seven-coordinate, adopting square face monocapped trigonal prismatic geometry, whereas the six coordinate uranium centres in $\mathbf{1}^{\mathbf{P}}$ and $\mathbf{1}^{\mathbf{M}}$ adopt distorted octahedral geometry. The dioxane adduct of $\mathbf{1}^{\mathbf{P}}$, ${ }_{1} \mathbf{P}$ (dioxane), also displays six coordinate uranium centres in distorted octahedral geometry. The equatorial plane is occupied by the aryloxide and iodide ligands, and the axial positions occupied by coordinated dioxane molecules. The exo-

Table 1 Selected reduction potentials versus $\mathrm{Fc}^{+} / \mathrm{Fc}$ measured in THF

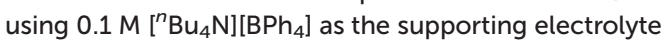

\begin{tabular}{ll}
\hline Compound & Reduction potential at $100 \mathrm{mV} \mathrm{s}^{-1} / \mathrm{V}$ \\
\hline $\mathbf{1}^{\mathbf{M}}$ & -2.03 \\
$\mathbf{2}^{\mathbf{M}}$ & -1.99 \\
$\mathbf{1}^{\mathbf{P}}$ & -2.05 \\
$\mathbf{2}^{\mathbf{P}}$ & -2.05 \\
$\mathbf{2}^{\mathbf{P}}$ & -1.53
\end{tabular}



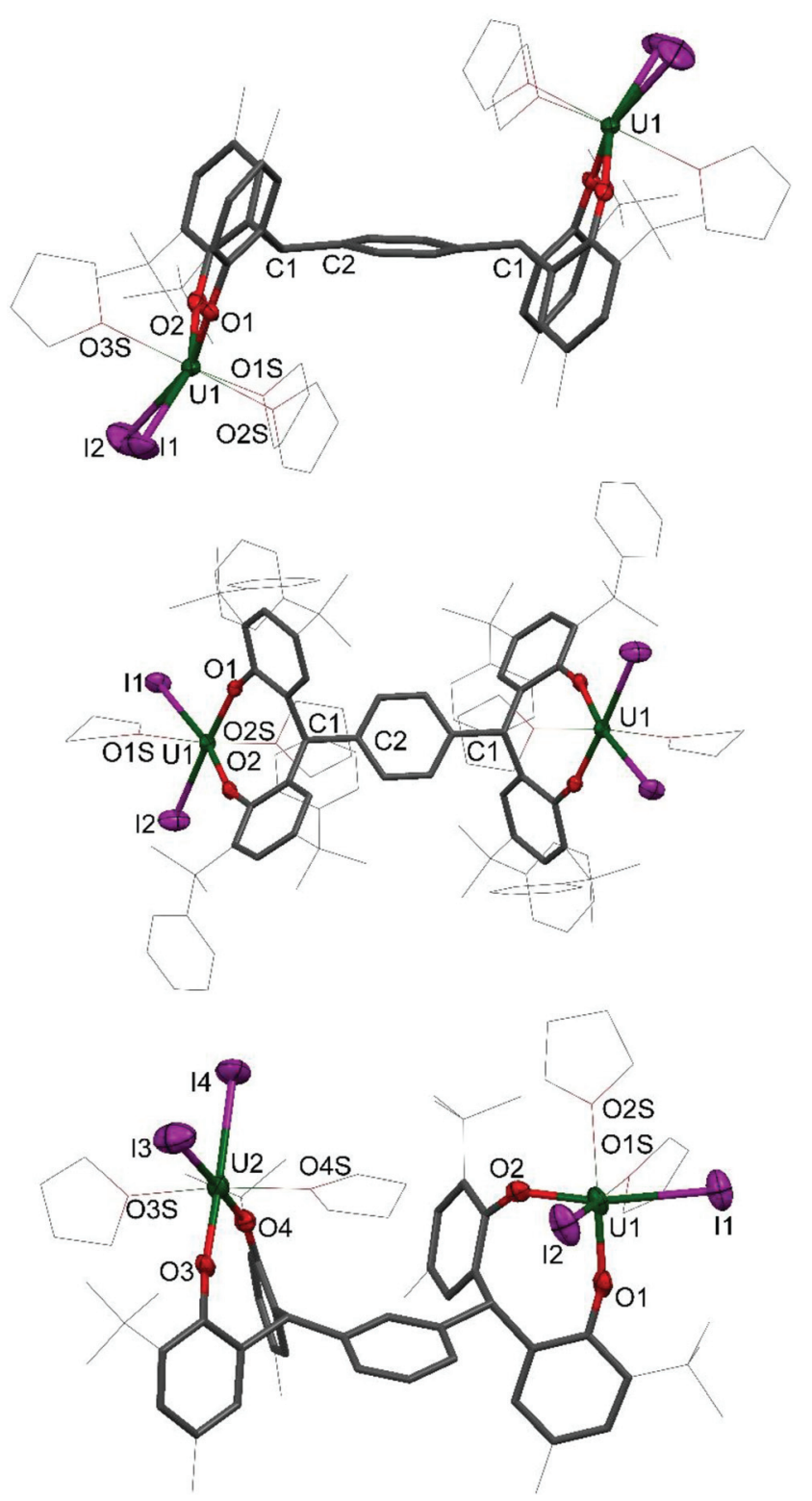

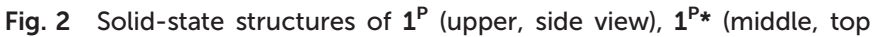
view) and $1^{M}$ (lower, side view). For clarity, hydrogen atoms and lattice solvent molecules are omitted (displacement ellipsoids are drawn at $50 \%$ probability, the remaining atoms and bonds shown as capped stick or wireframe). Selected bond lengths (Å) and angles $\left({ }^{\circ}\right)$ for $1^{P}$ : U1-O1 2.108(5), U1-O2 2.117(5), U1-I1 3.0970(8), U1-I2 3.1094(8), U1-O1-C11 157.4(4), U1-O1-C21 156.8(4). For $1^{P_{*}}$ : U1-O1 2.105(4), U1-O2 2.106(4), U1-I1 3.0553(4), U1-I2 3.0472(5), U1-O1-C11 152.9(3), U1-O1-C21 159.1(3). For $1^{\mathrm{M}}$ : U1-O1 2.132(12), U1-O2 2.080(11), U2-O3 2.110(9), U2-O4 2.129(10), U1-I1 3.0643(16), U1-I2 2.9860(14), U2-I3 3.0109(18), U2-14 3.0562(14), U1-O1-C11 138.7(9), U1-O1-C21 161.1(10), U2-O3C31 154.1(9), U2-O4-C41 156.0(9).

axial dioxanes act as a bridging ligand, linking the uranium centres in separate molecules to form a one-dimensional polymer in the solid state (see $\mathrm{ESI} \uparrow$ for further information).

The coordination environment of the two uranium centres in $\mathbf{1}^{\mathbf{M}}$ differs. While both metal centres have a pseudo-octahedral geometry, the aryloxide and iodide ligands occupy the

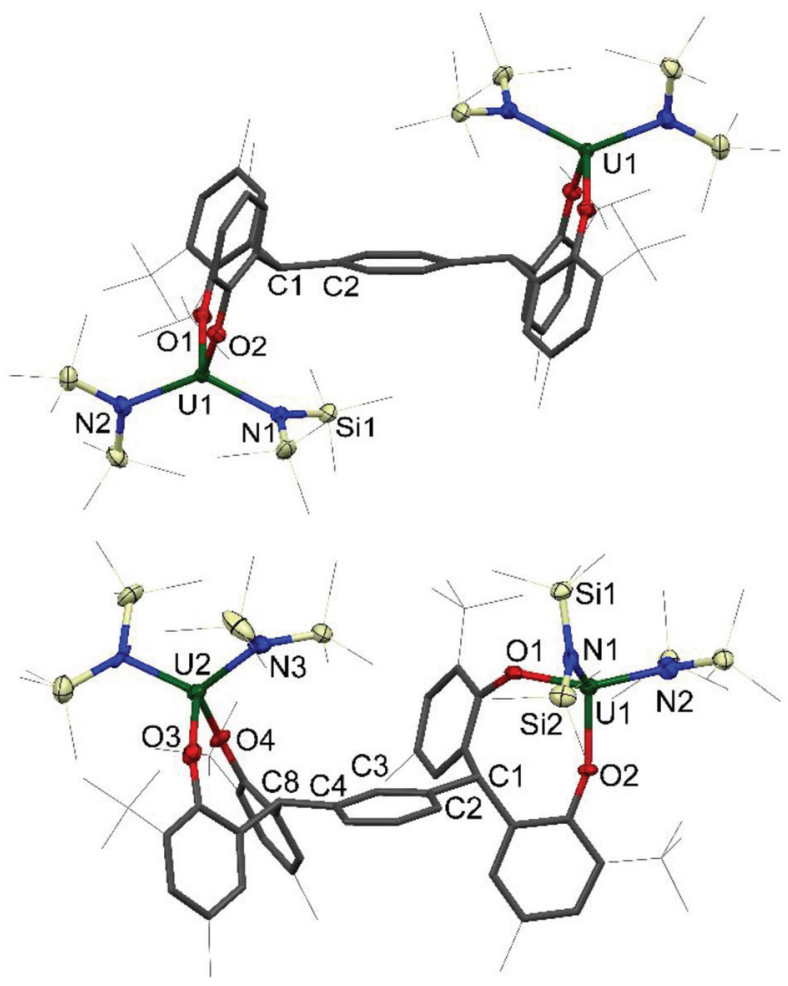

Fig. 3 Solid-state structures of $2^{P}$ (upper, side view), and $2^{M}$ (lower, side view). For clarity, all methyl groups, hydrogen atoms, and lattice solvent molecules are omitted (displacement ellipsoids are drawn at $50 \%$ probability, the remaining atoms and bonds shown as capped stick). For $2^{\mathrm{P} *}$ see ESI. $\dagger$ Selected bond lengths $(\AA)$ and angles $\left(^{\circ}\right)$ for $2^{\mathrm{P}}$ : U1-O1 2.1033(13), U1-O2 2.1362(13), U1-N1 2.2580(16), U1-N2 2.2479(17), U1O1-C11 152.17(12), U1-O2-C21 146.77(12); $2^{\mathrm{M}}$ : U1-O1 2.130(4), U1-O2 2.110(4), U2-O3 2.138(5), U2-O4 2.112(4), U1-N1 2.265(5), U1-N2 2.254(6), U2-N3 2.228(5), U2-N4 2.264(6), U1-O1-C11 141.5(4), U1-O2-C21 157.1(4) U2-O3-C31 138.5(4), U2-O4-C41 157.4(4).

equatorial plane about $\mathrm{U} 2$ with the axial positions occupied by THF donor molecules in a trans arrangement. The THF donors about the U1 centre, however, are mutually cis occupying one equatorial and one axial position. The two iodides and one aryloxide group occupy the three remaining equatorial positions and the other aryloxide occupies the axial position. This surprising feature results in unsymmetrical bond lengths and angles in the solid state. The $\mathrm{U} 1-\mathrm{O} 2$ bond length is slightly shorter than the average of the three other bond lengths

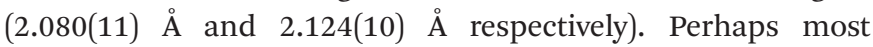
notable is the distortion of the U1-O1-C $\mathrm{C}_{i p s o}$ angle of $138.7(9)^{\circ}$ compared to the average of the other three angles, $157.0(9)^{\circ}$.

The U-OAr bond distances in $\mathbf{1}^{\mathbf{P}}, \mathbf{1}^{\mathbf{P}}$ and $\mathbf{1}^{\mathbf{M}}$ are very similar, with average distances of 2.112(5) $\AA$, 2.106(4) $\AA$ and $2.120(10) \AA$ respectively. These are comparable to previously reported uranium(Iv) bis(aryloxo) bis(iodo) complexes such as $\mathrm{I}_{2} \mathrm{U}(\mathrm{ODtbp})_{2}$ (thf) (ODtbp $=O-2,6{ }^{-}{ }^{t} \mathrm{Bu}_{2} \mathrm{C}_{6} \mathrm{H}_{4}$ ) with an average $\mathrm{U}-\mathrm{O}$ bond length of $2.076 \AA{ }^{14}$ and $\mathrm{I}_{2} \mathrm{U}(\mathrm{OAr})_{2}(\mathrm{thf})_{3}(\mathrm{Ar}=$ O-4- ${ }^{t} \mathrm{BuC}_{6} \mathrm{H}_{4}, \mathrm{O}-2,6-\mathrm{Me}_{2} \mathrm{C}_{6} \mathrm{H}_{3}, \mathrm{C}_{6} \mathrm{~F}_{5}$ ) with average U-O distances

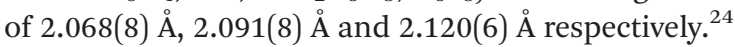


Table 2 Comparison of key metrics for the di-uranium complexes

\begin{tabular}{|c|c|c|c|c|c|c|}
\hline Distance $(\AA) /$ angle $\left(^{\circ}\right)$ & $1 p$ & $1^{*}$ & $1 \mathrm{~m}$ & $2 p$ & $2^{*}$ & $2 \mathrm{~m}$ \\
\hline $\mathrm{U}-\mathrm{O}$ & 2.112 & 2.106 & 2.112 & 2.120 & 2.142 & 2.122 \\
\hline $\mathrm{U}-\mathrm{N}$ & - & - & - & 2.253 & 2.267 & 2.252 \\
\hline OUO & 88.98 & 91.26 & 92.80 & 98.49 & 96.53 & 98.14 \\
\hline IUI & 81.6 & 84.0 & 91.8 & - & - & - \\
\hline NUN & - & - & - & 127.0 & 107.2 & 115.2 \\
\hline
\end{tabular}

The $\mathrm{U}-\mathrm{O}-\mathrm{C}_{i p s o}$ bond angles for the $\mathbf{1}^{\mathbf{R}}$ complexes are bent, reminiscent of the homoleptic uranium(IV) complex $\mathrm{U}(\mathrm{ODtbp})_{4},{ }^{25}$ with angles of $157.1(4)^{\circ}, 156.0(3)^{\circ}, 152.4(9)^{\circ}$ for $\mathbf{1}^{\mathbf{P}}, \quad \mathbf{1}^{\mathbf{P}}{ }^{*}$ and $\mathbf{1}^{\mathbf{M}}$ respectively, compared to $154.04(8)^{\circ}$ for $\mathrm{U}(\mathrm{ODtbp})_{4}$. This is somewhat unusual, as the $\mathrm{U}-\mathrm{O}-\mathrm{C}_{i p s o}$ bond angles of other complexes of the type $\mathrm{I}_{2} \mathrm{U}(\mathrm{OAr})_{2}$ fall within the range $166.2(8)^{\circ}$ to $176.9(8)^{\circ}$, and could be ascribed to the constraints imposed by the ligand frame.

The four-coordinate uranium centres in complexes $2^{\mathbf{P}}, 2^{\mathbf{P}_{*}}$ and $2^{\mathbf{M}}$ all adopt a distorted tetrahedral geometry. As shown in Table 2, the complexes have comparable average $\mathrm{U}-\mathrm{O}$ bond distances of 2.1198(13) $\AA, 2.1422(19) \AA$ and 2.122(4) A respectively, which is also true of the U-N bond distances of 2.2530

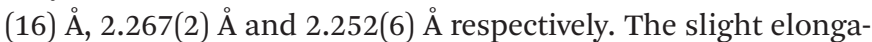
tion of $\mathrm{U}-\mathrm{O}$ and $\mathrm{U}-\mathrm{N}$ bonds in $2^{\mathbf{P}}{ }^{*}$ compared to $2^{\mathbf{P}}$ and $2^{\mathbf{M}}$ can be rationalised by the increased steric bulk around the metal centre in the larger tetraaryloxide framework interacting with the sterically demanding silylamide ligands. Similarly to the iodide complexes, the $\mathrm{U}-\mathrm{O}-\mathrm{C}_{i p s o}$ bond angles are closer to the homoleptic uranium(Iv) aryloxide, as opposed to the $\mathrm{I}_{2} \mathrm{U}(\mathrm{OAr})_{2}$ analogues, with mean angles of $149.47(12)^{\circ}, 150.72(17)^{\circ}$ and $148.5(4)^{\circ}$ for $2^{\mathbf{P}}, 2^{\mathbf{P}_{*}}$ and $2^{\mathbf{M}}$ respectively. The U-O bond distances are comparable to that of $\mathrm{U}(\mathrm{ODtbp})_{4}$, as well as the tetrahedral mixed aryloxo-amido uranium(Iv) complexes $\mathrm{Et}_{2} \mathrm{NU}$ (ODtbp) $)_{3}$ and $\mathrm{N}_{3}{ }_{3} \mathrm{U}(\mathrm{ODtbp})$ with average $\mathrm{U}-\mathrm{O}$ distances of

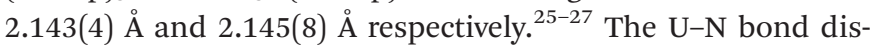
tances of $2^{\mathbf{R}}$ differ from the U-N distance of 2.161(5) $\AA$ exhibited by $\mathrm{Et}_{2} \mathrm{NU}(\mathrm{ODtbp})_{3}$ slightly, but agree very well with the U$\mathrm{N}$ bond distances exhibited by $\mathrm{N}_{3}{ }_{3} \mathrm{U}(\mathrm{ODtbp})$ and the uranium (v) complex $\mathrm{N}_{3}{ }_{3} \mathrm{U}\left(\right.$ Onapth) ${ }_{2}$ (napth $=\mathrm{C}_{10} \mathrm{H}_{7}$ ) of 2.284(10) $\AA$ and 2.222(6) $\AA$ respectively. ${ }^{21}$ This discrepancy in the U-N bond distance is presumably due to the difference in steric environment imposed by the bis(trimethylsilyl)amide ligand compared with that of the diethylamide ligand.

Inspection of the solid-state structures of these bimetallic derivatives, and of literature examples of other metal complexes suggests that the coordination of the two metals on the same side of the arene bridge is the preferred geometry in the meta-substituted $\mathrm{L}^{\mathrm{M}}$ complexes, ${ }^{18,20}$ but significantly rarer in the others, but is presumably not retained in solution for the smaller $\mathrm{R}$ substituted phenols. This could be due to the additional stability afforded by the generation of a dipole across the molecule.

\section{Conclusions}

Straightforward syntheses of dinuclear $\mathrm{U}^{\mathrm{IV}}$ complexes are possible using three different tetraphenolate ligands, in which a para- or meta-substituted phenyl backbone provide a strong yet flexible support to the two metal centres. The dinuclear $\mathrm{U}^{\mathrm{III}}$ analogues are most readily accessible by chemical reduction. The meta-arene bridged ligand appears to favour the coordination of both metals on the same side of the bridge, a factor which may enhance the ability to reductively couple certain small molecules.

Meta- and para-functionalised aryl imido and alkynide ligands have previously been used to demonstrate viable magnetic exchange between $f^{n}$ uranium centres. ${ }^{28,29}$ The properties are switched by changing the substitution patterns of the linking arene groups, and have been suggested to be of use in developing f-block magnetic materials for data storage, quantum computing or refrigeration applications. In addition to reactivity studies of these new potential multi-electron reductants, work is in progress to understand the magnetic behaviour of these new complexes.

\section{General details}

All moisture and air sensitive materials were manipulated using standard high-vacuum Schlenk-line techniques and MBraun gloveboxes and stored under an atmosphere of dried and deoxygenated dinitrogen. All gases were supplied by BOC gases UK. All glassware items, cannulae and Fisherbrand $1.2 \mu \mathrm{m}$ retention glass microfibre filters were dried in a $160^{\circ} \mathrm{C}$ oven overnight before use.

Tetrahydrofuran and hexane for use with moisture and air sensitive compounds were dried using a Vac Atmospheres solvent purification system and stored over activated 4 Å molecular sieves. The solvent was cycled through a drying column containing molecular sieves for 12 hours before collection. 1,4Dioxane for use with moisture and air sensitive compounds was refluxed over sodium for 3 days, distilled and collected into an ampoule containing $4 \AA$ molecular sieves. All solvents were degassed and stored for 2 days prior to use. $d_{6}$-Benzene and $d_{8}$-tetrahydrofuran were freeze pump thaw degassed, refluxed over potassium for 24 hours and distilled by trap to 
trap distillation prior to use. All solvents were purchased from Sigma-Aldrich or Fisher Scientific.

Unless stated otherwise, all NMR spectroscopic analyses were recorded at $298 \mathrm{~K}$ using a Bruker Avance III $500.12 \mathrm{MHz}$ spectrometer with ${ }^{1} \mathrm{H}$ NMR spectra run at $500.12 \mathrm{MHz}$, and ${ }^{29} \mathrm{Si}$ NMR spectra at $99.37 \mathrm{MHz}$. The ${ }^{1} \mathrm{H}$ NMR spectra were referenced internally using residual solvent signals and are reported relative to external tetramethylsilane. Chemical shifts are quoted in ppm and coupling constants in Hz.

\section{Experimental details}

Potassium and sodium metal, 2-tert-butyl-4-methylphenol, 2,4bis(dimethylbenzyl)phenol, terephthalaldehyde and isophthalaldehyde were purchased from Sigma-Aldrich and used as received. $\mathrm{KN}\left(\mathrm{SiMe}_{3}\right)_{2},{ }^{30}\left[\mathrm{Ca}\left(\mathrm{N}\left(\mathrm{SiMe}_{3}\right)_{2}\right]_{2},{ }^{31} \mathrm{UI}_{4} \cdot \text { (dioxane }\right)_{2},{ }^{32}$ $\left(\left(\left(\mathrm{Me}_{3} \mathrm{Si}\right)_{2}\right) \mathrm{N}\right)_{2} \mathrm{U}\left[\mathrm{K}^{2}-\mathrm{N}\left(\mathrm{SiMe}_{3}\right) \mathrm{SiMe}_{2} \mathrm{CH}_{2}\right]^{33}$ and $\mathrm{KC}_{8}$ were synthesised as previously described in literature procedures. ${ }^{34}$

\section{$\mathbf{H}_{4} \mathbf{L}^{\mathrm{p}}$}

A two necked $250 \mathrm{~cm}^{3}$ round bottom flask was charged with 2-tert-butyl-4-methylphenol ( $41.80 \mathrm{~g}, 250 \mathrm{mmol}, 4.4$ eq.), terephthalaldehyde ( $7.5 \mathrm{~g}, 56 \mathrm{mmol}, 1 \mathrm{eq}$.) and $p$-toluenesulfonic acid (1.06 g, $5.6 \mathrm{mmol}, 0.1 \mathrm{eq}$.) and equipped with a stirrer bar and an oil bubbler. The flask was placed under nitrogen flow, stirred and heated to $110{ }^{\circ} \mathrm{C}$. The solids melted to yield a yellow solution, which darkened with time. After circa 2 hours, the reaction mixture had turned to a reddish solid. The flask was allowed to cool to room temperature, at which point $50 \mathrm{~cm}^{3}$ of $20 \% \mathrm{H}_{2} \mathrm{O}$ in $\mathrm{MeCN}$ solution was added. The resulting beige suspension was filtered to provide an off-white solid which was collected and washed with boiling ethanol. The resulting colourless solid was dried under vacuum at $65{ }^{\circ} \mathrm{C}$ overnight and stored in a glove box. Yield $27 \mathrm{~g}(64 \%)$.

${ }^{1} \mathrm{H}$ NMR $\left(\mathrm{C}_{6} \mathrm{D}_{6}, 500 \mathrm{MHz}\right): \delta 7.12$ (Aryloxide $\mathrm{H}, J=1.9 \mathrm{~Hz}$, 4H), 7.06 (Aromatic H, 4H), 6.72 (Aryloxide $\mathrm{H}, J=1.9 \mathrm{~Hz}, 4 \mathrm{H}$ ), $5.56\left(\mathrm{Ar}_{3} \mathrm{CH}, 2 \mathrm{H}\right), 4.95(\mathrm{ArOH}, 4 \mathrm{H}), 2.06\left(\mathrm{C}_{3}, 12 \mathrm{H}\right), 1.44$ ( $\left.{ }^{\mathrm{B}} \mathrm{Bu} \mathrm{H}, 36 \mathrm{H}\right)$.

${ }^{13} \mathrm{C}$ NMR $\left(126 \mathrm{MHz}, \mathrm{C}_{6} \mathrm{D}_{6}\right) \delta 151.2,140.0,137.6,130.1$, 129.6, 128.1, (Aromatic C), $47.2\left(\mathrm{Ar}_{3} \mathrm{CH}\right), 34.6\left(\mathrm{C}_{\left.\left(\mathrm{CH}_{3}\right)_{3}\right), 29.6}\right.$ $\left(\mathrm{C}\left(\mathrm{CH}_{3}\right)_{3}\right), 20.7\left(\mathrm{CH}_{3}\right)$.

Mass Spectrometry: (ESI) $m / z 777.4850\left[\mathrm{~L}^{\mathrm{P}}+\mathrm{Na}\right]^{+}$.

\section{$\mathbf{H}_{4} \mathbf{L}^{\mathrm{m}}$}

A two necked $250 \mathrm{~cm}^{3}$ round bottom flask was charged with 2-tert-butyl-4-methylphenol (26.94 g, $161 \mathrm{mmol}, 4.4$ eq.), isophthalaldehyde $(5.0 \mathrm{~g}, 37 \mathrm{mmol}, 1 \mathrm{eq}$.$) and p$-toluenesulfonic acid $(0.71 \mathrm{~g}, 3.8 \mathrm{mmol}, 0.1 \mathrm{eq}$.) and equipped with a stirrer bar and an oil bubbler. The flask was placed under nitrogen flow, stirred and heated to $110{ }^{\circ} \mathrm{C}$. The solids melted to yield a yellow solution, which darkened with time. After circa 2 hours, the reaction mixture had turned to a reddish solid. The flask was allowed to cool to room temperature, at which point $30 \mathrm{~cm}^{3}$ of MeCN was added. The resulting beige suspension was filtered to provide a colourless solid which was collected by filtration and washed with MeCN. The resulting colourless solid was dried under vacuum at $65{ }^{\circ} \mathrm{C}$ overnight and stored in a glove box. Yield $22.9 \mathrm{~g}(82 \%)$.

${ }^{1} \mathrm{H}$ NMR $\left(\mathrm{C}_{6} \mathrm{D}_{6}, 500 \mathrm{MHz}\right) \delta 7.09$ (Aryloxide $\mathrm{H}, \mathrm{s}, 4 \mathrm{H}$ ), 7.06-6.96 (Aromatic H, m, 4H), 6.68 (Aryloxide H, s, 4H), 5.47 $\left(\mathrm{Ar}_{3} \mathrm{CH}, \mathrm{s}, 2 \mathrm{H}\right), 4.90(\mathrm{ArOH}, \mathrm{s}, 4 \mathrm{H}), 2.05\left(\mathrm{CH}_{3}, \mathrm{~s}, 12 \mathrm{H}\right), 1.43\left({ }^{t} \mathrm{Bu}\right.$ $\mathrm{H}, \mathrm{s}, 36 \mathrm{H})$.

${ }^{13} \mathrm{C}$ NMR $\left(\mathrm{C}_{6} \mathrm{D}_{6}, 126 \mathrm{MHz}\right) \delta 151.1,141.8,137.6,130.7$, 129.6, 128.4, 128.0 (Aromatic C), $47.6\left(\mathrm{Ar}_{3} \mathrm{CH}\right), 34.5\left(\mathrm{C}\left(\mathrm{CH}_{3}\right)_{3}\right)$, $29.61\left(\mathrm{C}\left(\mathrm{CH}_{3}\right)_{3}\right), 20.73\left(\mathrm{CH}_{3}\right)$.

Elemental analysis: $\mathrm{C} \quad 82.71 \%, \quad \mathrm{H} \quad 8.81 \%$ calculated. C $82.83 \%, 8.92 \%$ found.

Mass Spectrometry: (ESI) $m / z 777.4850\left[\mathrm{~L}^{\mathrm{M}}+\mathrm{Na}\right]^{+}$.

\section{$\mathbf{H}_{4} \mathbf{L}^{\mathbf{P}^{*}}$}

Analogous procedure to that used to synthesise $\mathrm{H}_{4} \mathrm{~L}^{\mathrm{P}}$. $82 \%$ yield.

${ }^{1} \mathrm{H}$ NMR $\left(\mathrm{C}_{6} \mathrm{D}_{6}, 600 \mathrm{MHz}\right) \delta 7.34-7.28$ (Aromatic H, 12H), 7.20 (Aromatic H, 8H), 7.12 (Aromatic H, 8H), 7.07 (Aromatic $\mathrm{H}, 4 \mathrm{H}$ ), 7.03 (Aromatic H, 4H), 6.99 (Aromatic $\mathrm{H}, 8 \mathrm{H}$ ), 6.96-6.90 (Aromatic H, 4H), 6.89 (Aromatic H, 4H), 5.98 $\left(\mathrm{Ar}_{3} \mathrm{C} \underline{\mathrm{H}}, 2 \mathrm{H}\right), 4.48(\mathrm{ArOH}, 4 \mathrm{H}), 1.65\left(\mathrm{C}_{3}, 24 \mathrm{H}\right), 1.47\left(\mathrm{C}_{3}\right.$, $24 \mathrm{H})$.

${ }^{13} \mathrm{C}$ NMR $\left(\mathrm{C}_{6} \mathrm{D}_{6}, 151 \mathrm{MHz}\right) \delta 151.6,150.2,149.4,142.0$, $140.8,135.4,131.6,129.4,129.0,127.4,127.1,126.6,126.1$, 125.8, 124.0 (Aromatic C), $44.6\left(\mathrm{Ph}_{3} \mathrm{CH}\right), 43.0\left(\mathrm{CCH}_{3}\right), 42.3$ $\left(\mathrm{CCH}_{3}\right), 31.4\left(\mathrm{CH}_{3}\right), 31.3\left(\mathrm{CH}_{3}\right), 30.0\left(\mathrm{CH}_{3}\right), 29.8\left(\mathrm{CH}_{3}\right)$.

Mass Spectrometry: (ESI) $m / z 1441.7983\left[\mathrm{~L}^{\mathrm{P} *}+\mathrm{Na}\right]^{+}$.

\section{$1^{\mathrm{P}}\left(\mathbf{U}_{2} \mathbf{I}_{4} \mathbf{L}^{\mathrm{P}}\right)$}

Two $100 \mathrm{~mL}$ Schlenk flasks were charged respectively with $\left[\mathrm{CaN}_{2}\right]_{2}(0.978 \mathrm{~g}, 1.36 \mathrm{mmol})$ and $\mathrm{H}_{4} \mathrm{~L}^{\mathrm{P}}(1.024 \mathrm{~g}, 1.36 \mathrm{mmol})$ and equipped with stirrer bars. $30 \mathrm{~mL}$ of 1,4-dioxane was added to both solids to provide off-white solutions. The solutions were combined into one Schlenk with vigorous stirring and stirred for an hour at room temperature, to provide an offwhite suspension. To a $250 \mathrm{~mL}$ Schlenk flask containing $\mathrm{UI}_{4}\left(\mathrm{OC}_{4} \mathrm{H}_{8} \mathrm{O}\right)_{2}$ and a stirrer bar, $100 \mathrm{~mL}$ of 1,4-dioxane was

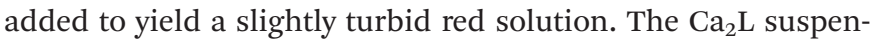
sion generated in situ was added to the $\mathrm{UI}_{4}\left(\mathrm{OC}_{4} \mathrm{H}_{8} \mathrm{O}\right)_{2}$ solution with vigorous stirring. Once the addition was complete, the reaction was left to stir for 48 hours to yield a light green suspension. The green brown solution was filtered and isolated from the colourless precipitate, and the solvent removed to give a yellow-brown solid (1.75 g, 65\%). Crystals suitable for single crystal X-ray analysis were grown from slow evaporation of concentrated benzene, dioxane or THF solutions at room temperature.

${ }^{1} \mathrm{H}$ NMR (500 MHz, $329 \mathrm{~K}$, THF- $d_{8}$ ) $\delta 12.68$ (Aryl, $4 \mathrm{H}$ ), 10.39 (Aryl, $4 \mathrm{H}), 8.89\left(\mathrm{Ar}_{3} \mathrm{CH}, 2 \mathrm{H}\right), 6.63(t-\mathrm{Bu}, 36 \mathrm{H}), 4.25(\mathrm{Me}, 12 \mathrm{H})$, 3.94 (Aryl, 4H).

Elemental analysis (dioxane adduct): C $38.45 \%, \mathrm{H} 4.34 \%$ calculated. C $36.62 \%, \mathrm{H} 4.36 \%$ found. 
$\mathbf{1}^{\mathbf{P} *}\left(\mathbf{U}_{2} \mathbf{I}_{4} \mathbf{L}^{\mathbf{P}}\right)$

Made analogously to $\mathrm{U}_{2} \mathrm{I}_{4} \mathrm{~L}^{\mathrm{P}}$. Green plates suitable for X-ray diffraction were grown from slow evaporation of a THF solution.

${ }^{1} \mathrm{H}$ NMR $\left(d_{8}\right.$-THF, $\left.329 \mathrm{~K}, 500 \mathrm{MHz}\right) \delta 7.13$ (Aryl H, 2H), 7.08 (Aryl H, 8H), 6.98 (Aryl H, 4H), 6.94 (Aryl H, 4H), 6.84 (Aryl H, 2H), 6.69 (Aryl H, 2H), 6.57 (Aryl H, 8H), 6.47 (Aryl H, 4H), 6.42 (Aryl H, 2H), 5.65 (Aryl H, 4H), $2.31\left(\mathrm{Ar}_{3} \mathrm{CH}, 1 \mathrm{H}\right), 2.21\left(\mathrm{Ar}_{3} \mathrm{C} \underline{\mathrm{H}}\right.$, $1 \mathrm{H}), 1.45\left(\mathrm{CH}_{3}, 12 \mathrm{H}\right), 1.31$ (Aryl $\left.\mathrm{H}, 4 \mathrm{H}\right), 1.18\left(\mathrm{CH}_{3}, 12 \mathrm{H}\right), 1.02$ (Aryl H, 4H), 0.78 (Aryl H, 4H).

Elemental analysis: C $53.62 \%$, H $5.02 \%$ calculated. C $53.32 \%$, H $5.16 \%$ found.

\section{$\mathbf{1}^{\mathbf{M}}\left(\mathbf{U}_{2} \mathbf{I}_{4} \mathbf{L}^{\mathbf{M}}\right)$}

A Schlenk flask was charged with $\mathrm{H}_{4} \mathrm{~L}^{\mathrm{M}}(1.00 \mathrm{~g}, 1.32 \mathrm{mmol})$ and $\mathrm{KN}^{\prime \prime}$ (1.06 g, $5.30 \mathrm{mmol}$ ) and equipped with a stirrer bar. THF was added and the yellow solution was stirred for 1 hour at room temperature. To this solution, $\mathrm{UI}_{4}\left(\mathrm{OC}_{4} \mathrm{H}_{8} \mathrm{O}\right)_{2}(2.44 \mathrm{~g}$, $2.65 \mathrm{mmol}$ ) in THF was added by cannula transfer from a separate Schlenk flask. The resulting dark green solution was stirred at room temperature for 48 hours, yielding a pale green suspension. The colourless precipitate was removed by filtration and the solvent was removed under reduced pressure giving a light green solid. (1.87 g, 82\%). Green plate crystals suitable for single crystal X-ray analysis were grown from slow evaporation of concentrated benzene or thf solutions at room temperature.

${ }^{1} \mathrm{H}$ NMR $\left(d_{8}\right.$-THF, $\left.329 \mathrm{~K}, 500 \mathrm{MHz}\right) \delta 13.94$ (Aryloxide $\mathrm{H}$, $4 \mathrm{H}$ ), 7.53 (Aryloxide $\mathrm{H}, 4 \mathrm{H}), 7.18(t-\mathrm{Bu} \mathrm{H}, 36 \mathrm{H}), 6.92$ (Aromatic $\mathrm{H}, 1 \mathrm{H}$ ), $5.93\left(\mathrm{CH}_{3}, 12 \mathrm{H}\right.$ ), 5.60 (Aromatic $\mathrm{H}, 1 \mathrm{H}$ ), 2.20 (Aromatic $\mathrm{H}, 2 \mathrm{H}), 0.90\left(\mathrm{Ar}_{3} \mathrm{CH}, 2 \mathrm{H}\right)$.

Elemental analysis: C $40.37 \%, \quad \mathrm{H} \quad 4.68 \%$ calculated. C $40.27 \%, 4.55 \%$ found.

\section{$2^{\mathrm{P}}\left(\mathrm{U}_{2} \mathbf{N}_{4} \mathbf{L}^{\mathbf{P}}\right)$}

A Schlenk flask was charged with $\mathrm{H}_{4} \mathrm{~L}^{\mathrm{P}}(100 \mathrm{mg}, 0.133 \mathrm{mmol})$ and $\mathrm{U}\left(\mathrm{N}^{\prime \prime}\right)_{2}\left(\mathrm{~N}\left\{\mathrm{SiMe}_{3}\right\} \mathrm{SiMe}_{2} \mathrm{CH}_{2}\right)\left(\mathrm{N}^{\prime \prime}=\mathrm{N}\left(\mathrm{SiMe}_{3}\right)_{2}\right)(200 \mathrm{mg}$, $0.278 \mathrm{mmol}, 2.1$ eq.), a stirrer bar and hexanes $(15 \mathrm{ml})$. The resulting dark brown suspension was allowed to stir at room temperature for $16 \mathrm{~h}$ during which time a colour change to olive green occurred. The reaction mixture was allowed to stand, and the off-white precipitate was isolated by filtration. The product was recrystallized from benzene solutions allowed to stand at room temperature to afford yellow plates of $\mathrm{U}_{2} \mathrm{~N}^{\prime \prime}{ }_{4} \mathrm{~L}^{\mathrm{P}} 2^{\mathrm{P}}$ in $65 \%$ yield (247 mg). The yellow blocks were suitable for single crystal X-ray diffraction analysis.

${ }^{1} \mathrm{H}$ NMR $\left(\mathrm{C}_{6} \mathrm{D}_{6}, 500 \mathrm{MHz}\right) \delta 35.34$ (Aryloxide $\left.\mathrm{H}, 4 \mathrm{H}\right), 19.97$ (Aryloxide $\mathrm{H}, 4 \mathrm{H}), 5.51$ (Aromatic $\mathrm{H}, 4 \mathrm{H}), 4.40\left(\mathrm{CH}_{3}, 12 \mathrm{H}\right.$ ), $-2.90\left(\mathrm{Ar}_{3} \mathrm{CH}, 2 \mathrm{H}\right),-9.62(t-\mathrm{BuH}, 36 \mathrm{H}),-18.89\left(\mathrm{SiCH}_{3}, 72 \mathrm{H}\right)$.

${ }^{29} \mathrm{Si} \mathrm{NMR}\left(\mathrm{C}_{6} \mathrm{D}_{6}, 99.4 \mathrm{MHz}\right) \delta-234.6\left(\mathrm{Me}_{3} \mathrm{Si}\right)$.

Elemental analysis: C $48.85 \%, \mathrm{H} 7.23 \%, \mathrm{~N} 3.00 \%$ calculated. C $48.03 \%$, H 7.10\%, N 2.90\% found.

\section{$2^{\mathbf{M}}\left(\mathbf{U}_{2} \mathbf{N}^{\prime \prime} \mathbf{L}^{\mathbf{M}}\right)$}

Made by an analogous procedure with recrystallisation by slow diffusion of hexane vapour into concentrated THF solu- tions to give green blocks suitable for single crystal X-ray diffraction analysis in $60 \%$ yield.

${ }^{1} \mathrm{H}$ NMR $\left(\mathrm{C}_{6} \mathrm{D}_{6}, 500 \mathrm{MHz}\right) \delta 41.19$ (Aromatic $\mathrm{H}, 2 \mathrm{H}$ ), 31.62 (Aromatic H, 1H), 27.73 (Aromatic H, 1H), 16.71 (Aryloxide $\mathrm{H}$, 4H), 3.90 (Aryloxide $\mathrm{H}, 4 \mathrm{H}), 1.50\left(\mathrm{CH}_{3}, 12 \mathrm{H}\right),-3.03\left(\mathrm{Ar}_{3} \mathrm{C} \underline{\mathrm{H}}\right.$, $2 \mathrm{H}),-9.76(t-\mathrm{BuH}, 36 \mathrm{H}),-18.51\left(\mathrm{SiCH}_{3}, 72 \mathrm{H}\right) \mathrm{ppm} ;{ }^{29} \mathrm{Si} \mathrm{NMR}$ $\left(\mathrm{C}_{6} \mathrm{D}_{6}, 99.4 \mathrm{MHz}\right) \delta-230.8\left(\mathrm{Me}_{3} \mathrm{Si}\right)$.

Elemental analysis: C 48.85\%, H 7.23\%, N 3.00\% calculated. C $48.66 \%, 6.91 \%$, N $2.78 \%$ found.

\section{$2^{\mathbf{P}_{*}}\left(\mathbf{U}_{2} \mathbf{N}^{\prime \prime} \mathbf{L}^{\mathbf{P}_{*}}\right)$}

Made by an analogous procedure. Green plates isolated in 65\% yield. Single crystals suitable for X-ray diffraction were grown by diffusion of hexanes into a THF solution of $2^{*}$.

${ }^{1} \mathrm{H}$ NMR (500 MHz, THF- $d_{8}$ ) $\delta 13.12$ (Aromatic H, 4H), 11.89 (Aromatic H, 8H), 9.05 (Aromatic H, 4H), $7.56(\mathrm{Me} \mathrm{H,} \mathrm{12H),}$ 7.16 (Aromatic H, 8H), 7.05 (Aromatic H, 4H), 6.74 (Aromatic $\mathrm{H}, 4 \mathrm{H}$ ), 6.65 (Aromatic H, 8H), 6.37 (Me H, 12H), 1.59 (Me H, 12H), 1.26 (Me H, 12H).

Elemental analysis: C $60.68 \%, \mathrm{H} 6.92 \%, \mathrm{~N} 2.21 \%$ calculated. C $60.51 \%$, H 6.93\%, N 1.99\% found.

\section{$3^{\mathrm{M}}\left(\mathrm{U}_{2} \mathbf{N}_{2}{ }_{2} \mathbf{L}^{\mathrm{M}}\right)$}

A Schlenk flask was charged with $\mathbf{U}_{2} \mathbf{N}_{4}{ }_{4} \mathbf{L}^{\mathbf{M}}$ (274 mg, $0.223 \mathrm{mmol}$ ) and $\mathrm{KC}_{8}$ (64 $\mathrm{mg}, 0.447 \mathrm{mmol}$ ) and equipped with a stirrer bar. Toluene was added and the resulting dark green solution was stirred for 16 hours at room temperature, turning dark purple. The toluene was removed under reduced pressure and the product was extracted into heptane. The dark purple product was obtained as a powder following removal of volatiles under reduced pressure, $(0.31 \mathrm{~g}, 74 \%)$.

${ }^{1} \mathrm{H}$ NMR $\left(\mathrm{C}_{6} \mathrm{D}_{6}, 500 \mathrm{MHz}\right) \delta 22.22$ (Aromatic $\mathrm{H}, 2 \mathrm{H}$ ), 17.50 (Aromatic H, 1H), 14.62 (Aromatic H, 1H), 11.85 (Aryloxide $\mathrm{H}$, $4 \mathrm{H}), 7.50$ (Aryloxide $\mathrm{H}, 4 \mathrm{H}), 2.11\left(\mathrm{CH}_{3}, 12 \mathrm{H}\right), 0.89\left(\mathrm{Ar}_{3} \mathrm{C} \underline{\mathrm{H}}, 2 \mathrm{H}\right)$, -7.94 (s, 36H, $\left.{ }^{t} \mathrm{Bu}-H\right),-13.33$ (s, 36 $\left.\mathrm{H}, \mathrm{SiCH}_{3}\right) \mathrm{ppm} ;{ }^{29} \mathrm{Si} \mathrm{NMR}$ $\left(\mathrm{C}_{6} \mathrm{D}_{6}, 99.4 \mathrm{MHz}\right) \delta-99.93\left(\mathrm{Me}_{3} \mathrm{Si}\right)$.

Elemental analysis: C $49.66 \%, \mathrm{H} 6.38 \%, \mathrm{~N} 1.81 \%$ calculated. C $49.66 \%$, H $6.38 \%$, N $1.81 \%$ found.

\section{Acknowledgements}

We thank EaStCHEM, the University of Edinburgh and the Engineering and Physical Sciences Research Council EPSRC, grants EP/H004823/1 and EP/M010554/1. PLA also thanks the Technische Universität München - Institute for Advanced Study, funded by the German Excellence Initiative.

\section{Notes and references}

1 P. L. Arnold, Chem. Commun., 2011, 47, 9005.

2 H. S. La Pierre and K. Meyer, in Progress in Inorganic Chemistry, John Wiley \& Sons, Inc., Hoboken, New Jersey, 2014, vol. 58. 
3 W. J. Evans, S. A. Kozimor and J. W. Ziller, J. Am. Chem. Soc., 2003, 125, 14264-14265.

4 J. G. Brennan, R. A. Andersen and J. L. Robbins, J. Am. Chem. Soc., 1986, 108, 335-336.

5 P. L. Arnold, Z. R. Turner, R. M. Bellabarba and R. P. Tooze, Chem. Sci., 2011, 2, 77-79.

6 S. M. Mansell, J. H. Farnaby, A. I. Germeroth and P. L. Arnold, Organometallics, 2013, 32, 4214-4222.

7 P. L. Arnold, S. M. Mansell, L. Maron and D. McKay, Nat. Chem., 2012, 4, 668-674.

8 N. Tsoureas, O. T. Summerscales, F. G. N. Cloke and S. M. Roe, Organometallics, 2013, 32, 1353-1362.

9 N. Tsoureas, L. Castro, A. F. R. Kilpatrick, F. G. N. Cloke and L. Maron, Chem. Sci., 2014, 5, 3777.

10 P. L. Arnold, C. J. Stevens, J. H. Farnaby, M. G. Gardiner, G. S. Nichol and J. B. Love, J. Am. Chem. Soc., 2014, 136, 10218-10221.

11 P. L. Arnold, J. H. Farnaby, R. C. White, N. Kaltsoyannis, M. G. Gardiner and J. B. Love, Chem. Sci., 2014, 5, 756-765.

12 W. G. Van Der Sluys and A. P. Sattelberger, Chem. Rev., 1990, 90, 1027-1040.

13 W. G. Van Der Sluys, C. J. Burns, J. C. Huffman and A. P. Sattelberger, J. Am. Chem. Soc., 1988, 110, 59245925.

14 L. R. Avens, D. M. Barnhart, C. J. Burns, S. D. McKee and W. H. Smith, Inorg. Chem., 1994, 33, 4245-4254.

15 A. Walshe, J. Fang, L. Maron and R. J. Baker, Inorg. Chem., 2013, 52, 9077-9086.

16 R. J. Baker and A. Walshe, Chem. Commun., 2012, 48, 985-987.

17 M. Janssen, L. Bini, B. Hamers, C. Müller, D. Hess, A. Christiansen, R. Franke and D. Vogt, Tetrahedron Lett., 2010, 51, 1971-1975.

18 J. Zhang, C. Jian, Y. Gao, L. Wang, N. Tang and J. Wu, Inorg. Chem., 2012, 51, 13380-13389.
19 L. Tang, E. P. Wasserman, D. R. Neithamer, R. D. Krystosek, Y. Cheng, P. C. Price, Y. He and T. J. Emge, Macromolecules, 2008, 41, 7306-7315.

20 Y. Al-Khafaji, X. Sun, T. J. Prior, M. R. J. Elsegood and C. Redshaw, Dalton Trans., 2015, 44, 12349-12356.

21 A. Cottone and M. J. Scott, Organometallics, 2000, 19, 5254-5256.

22 D. E. Morris, R. E. Da Re, K. C. Jantunen, I. CastroRodriguez and J. L. Kiplinger, Organometallics, 2004, 23, 5142-5153.

23 A. Vallat, E. Laviron and A. Dormond, J. Chem. Soc., Dalton Trans., 1990, 921-924.

24 D. D. Schnaars, G. Wu and T. W. Hayton, Dalton Trans., 2009, 3681.

25 J. M. Berg, D. L. Clark, J. C. Huffman, D. E. Morris, A. P. Sattelberger, W. E. Streib, W. G. Van der Sluys and J. G. Watkin, J. Am. Chem. Soc., 1992, 114, 10811-10821.

26 P. B. Hitchcock, M. F. Lappert, A. Singh, R. G. Taylor and D. Brown, J. Chem. Soc., Chem. Commun., 1983, 561-563.

27 A. J. Lewis, K. C. Mullane, E. Nakamaru-Ogiso, P. J. Carroll and E. J. Schelter, Inorg. Chem., 2014, 53, 6944-6953.

28 R. K. Rosen, R. A. Andersen and N. M. Edelstein, J. Am. Chem. Soc., 1990, 112, 4588-4590.

29 B. S. Newell, A. K. Rappé and M. P. Shores, Inorg. Chem., 2010, 49, 1595-1606.

30 S. M. Mansell, B. F. Perandones and P. L. Arnold, J. Organomet. Chem., 2010, 695, 2814-2821.

31 O. Michel, C. Meermann, K. W. Törnroos and R. Anwander, Organometallics, 2009, 28, 4783-4790.

32 M. J. Monreal, R. K. Thomson, T. Cantat, N. E. Travia, B. L. Scott and J. L. Kiplinger, Organometallics, 2011, 30, 2031-2038.

33 A. Dormond, A. El Bouadili, A. Aaliti and C. Moise, J. Organomet. Chem., 1985, 288, C1-C5.

34 L. M. Viculis, J. J. Mack, O. M. Mayer, H. T. Hahn and R. B. Kaner, J. Mater. Chem., 2005, 15, 974. 